\title{
INFLUÊNCIA DA IDADE E DA POSIÇÃO RADIAL NA MASSA ESPECÍFICA DA MADEIRA DE Eucalyptus grandis Hill ex. MAIDEN
}

\author{
José de Castro Silva ${ }^{1}$ \\ José Tarcísio da Silva Oliveira ${ }^{2}$ \\ Mário Tomazello Filho ${ }^{3}$ \\ Sidon Keinert Júnior ${ }^{4}$ \\ Jorge Luis Monteiro de Matos ${ }^{4}$
}

\begin{abstract}
RESUMO
Este trabalho objetivou avaliar a variação da massa específica da madeira de Eucalyptus grandis, de quatro idades em diferentes posições radiais. Para os ensaios de massa específica básica e aparente, as amostras foram retiradas de seções radiais de três discos, retirados da base e do final da primeira e da segunda toras, com comprimentos comerciais de três metros, tomando-se quatro posições eqüidistantes $(0,33$, 66 e 100\%), no sentido medula-casca. Para o ensaio de densitometria de raios-X, as amostras foram retiradas dos mesmos discos, utilizando-se-se toda a seção radial. Em todos os ensaios, verificou-se que a madeira de dez anos apresentou os menores valores de massa específica, seguida da madeira de quatorze anos. Os maiores valores de massa específica foram encontrados na madeira de vinte anos, seguida da madeira de vinte e cinco anos. Em todas as idades, verificou-se um crescimento dos valores de massa específica no sentido radial medula-casca. Os resultados obtidos com a análise densitométrica foram semelhantes aos dados apresentados na análise de massa específica aparente.

Palavras-chave: Eucalyptus grandis, massa específica, idade, variação radial
\end{abstract}

INFLUENCE OF AGE AND RADIAL POSITION ON THE DENSITY OF THE WOOD OF Eucalyptus grandis HILL EX. MAIDEN

\begin{abstract}
The objective of this work was to evaluate the variation of wood specific gravity of Eucalyptus grandis of four ages and radial positions. Specific gravity samples were taken radial disks in the bark-to-pith direction at 0,33 , 66 and $100 \%$ of the radii. For the densitometry study samples were collected radially from disks at three positions of the stem. It was observed in all cases that 10 -year-old trees had the lowest values of specific gravity, fourteen-year-old trees came second. Heaviest wood was found in 20-year-old trees, while the older (25-year) trees were a little lighter. It was found in all ages, that specific gravity increased from the pith to the bark.

Key words: Eucalyptus grandis, specific gravity, tree age, radial variability
\end{abstract}

\section{INTRODUÇÃO}

A massa específica da madeira é o resultado de uma complexa combinação dos seus constituintes anatômicos. É uma propriedade muito importante e fornece inúmeras informações sobre as características da madeira, devido a sua íntima relação com várias outras propriedades, tornando-se um parâmetro muito utilizado para qualificar a

madeira, nos diversos segmentos da atividade industrial.Segundo Panshin e De Zeeuw (1980), a massa específica pode variar entre gêneros, espécies do mesmo gênero, árvores da mesma espécie e, até mesmo, entre diferentes partes da mesma árvore. Segundo Kollmann e Côté (1968), as variações da massa específica se devem às diferenças na estrutura anatômica

\footnotetext{
${ }^{1}$ Professor UFV/DEF/CEDAF, Departamento de Engenharia Florestal, UFV - 36.571-000, Viçosa, MG

${ }^{2}$ Professor do Departamento de Engenharia Rural, UFES, Caixa Postal 16 29.500-000, Alegre, ES

${ }^{3}$ Professor DCF/ESALQ/USP, Departamento de Ciências Florestais - ESALQ Av. Pádua Dias, 11 13.400-000 Piracicaba, SP

${ }^{4}$ Professor DETR/UFPR, Av. Lothário Meissner, 3400, Jardim Botânico, 80.210-170 Curitiba, PR
} 
da madeira e na quantidade de substâncias extrativas presentes por unidade de volume, em função, principalmente, da idade da árvore, genótipo, índice de sítio, clima, localização geográfica e tratos silviculturais. A estrutura da madeira a que se referem os autores está relacionada à espessura da parede celular, bem como às dimensões e à quantidade proporcional de diferentes tipos de células (fibras, traqueídeos, vasos, dutos de resina e parênquima). Vital (1987) afirma que os efeitos, em geral, são interativos e difíceis de serem avaliados isoladamente e, dificilmente, se consegue alterar uma propriedade sem que as demais sejam alteradas. Segundo Tsoumis (1991), a massa específica é uma medida da quantidade de material na parede celular, presente em certo volume e é, também, uma indicadora do volume de espaços vazios na madeira.

Chimelo (1980), Gérard et al. (1995) afirmaram que, quase sempre, a massa específica se apresenta correlacionada com a retratibilidade, secagem, trabalhabilidade, impregnabilidade, durabilidade natural e várias propriedades mecânicas da madeira. Englert (1966) reiterou que a qualidade da madeira sólida é quase sinônimo de sua massa específica, mas ressalta que tal propriedade não deve ser considerada como único parâmetro de decisão para um determinado uso. Oliveira et al. (1990), Lima et al. (2000) asseguraram que a massa específica é uma boa indicadora de qualidade da madeira, em função das várias correlações com outras propriedades; entretanto, ela não indica, de forma direta e conclusiva, valores das propriedades mecânicas, dimensões de fibras, poder calorífico, composição química ou existência de defeitos internos. Assim, a massa específica, quando analisada de forma isolada, não representa um bom e seguro parâmetro para uma definição de usos.

Ferreira e Kageyama (1978) verificaram um aumento proporcional da massa específica em função da idade, em várias espécies de Eucalyptus. Segundo Panshin e De Zeeuw (1980), Lima et al., (2000), a massa específica aumenta muito rapidamente durante o período juvenil, cresce mais lentamente, numa fase intermediária da idade, até se tornar mais ou menos constante, na fase da maturidade da árvore. Hillis e
Brown (1978), ao estudarem a madeira de Eucalyptus grandis, localizada na base das árvores e formada entre dezesseis e vinte anos, verificaram um acréscimo da massa específica de $25 \%$, quando comparada à madeira que se formou no período entre um e cinco anos. Os mesmos autores encontraram uma diferença de $40 \%$ nos valores da massa específica básica da madeira de Eucalyptus pilularis, quando a sua idade variou de um para trinta anos. Bhat et al. (1990) verificaram que a massa específica aumentou proporcionalmente com a idade ao estudarem a madeira de Eucalyptus grandis, de diferentes idades; os mesmos autores concluíram que as variações se prendiam a três fatores básicos: idade, ambiente e genótipo. Segundo Tomazello Filho (1985b), as variações da massa específica nos sentidos longitudinal/radial do tronco estão relacionadas com a idade da árvore, amostragem, genótipo e condições ambientais de crescimento. Variações no sentido basetopo têm sido constatadas em várias situações, porém, sem obedecer a um padrão bem definido; no sentido transversal, no entanto, uma tendência bem definida de aumento no sentido medula-casca tem sido observada e foi confirmada pelos resultados obtidos por Fonseca (1971), Tomazello Filho, (1985a), Tomazello Filho (1985b), Carmo (1996), Lima et al. (2000). Utilizando madeira de vinte e dois anos, Lima (1995) verificou que a massa específica aumentou, significativamente, da medula para o cerne periférico, ocorrendo pequeno decréscimo na região do alburno. Della Lucia e Vital (1983), estudando a madeira de Eucalyptus saligna, com quarenta anos de idade, verificaram que a madeira próxima à medula e ao alburno apresentaram, respectivamente, valores de massa específica 30 e $10 \%$ inferiores ao cerne. Bendtsen e Senft (1986) afirmaram que a massa específica pode ser explicada pelas diferenças anatômicas, devido às mudanças que ocorrem no lenho juvenil/adulto, que são mais acentuadas nas coníferas que nas folhosas. Os mesmos autores verificaram que o ângulo fibrilar é maior na região da medula ou próximo dela e diminui, rapidamente, em direção à casca, ocorrendo, paralelamente, um aumento rápido no diâmetro dos vasos; nessa região, as fibras são mais curtas, apresentam menores diâmetros e, geralmente, paredes são mais finas. Zobel e 
Jett (1995) sugeriram que, nas pesquisas de melhoramento e genética florestal, o delineamento da seleção de matrizes leve em consideração apenas as propriedades do lenho adulto, pois o valor genético do lenho juvenil é de reduzida importância.

A técnica de densitometria de raios-X é das mais avançadas para medir as variações de massa específica a pequenas distâncias, o que, segundo Oliveira (1997), é impossível pelo método gravimétrico convencional. A técnica para o estudo de madeira foi implantada no Brasil por Amaral (1994) e tem sido apontada como um importante instrumento de avaliação mais detalhada para estudar os efeitos dos tratamentos silviculturais na qualidade da madeira, bem como para explicar outros resultados ligados à caracterização tecnológica da madeira.
O presente trabalho teve como objetivo avaliar a variabilidade da massa específica da madeira de Eucalyptus grandis, de quatro idades $(10,14,20$ e 25 anos) e posições radiais $(0,33,66$ e $100 \%)$.

\section{MATERIAL E MÉTODOS}

O material utilizado neste estudo foi obtido de plantios comerciais de Eucalyptus grandis Hill ex. Maiden, com idades de dez, quatorze, vinte e vinte e cinco anos, procedentes da Fazenda Monte Alegre, da KLABIN Fabricadora de Papel e Celulose S. A., localizada no município de Telêmaco Borba, no Estado do Paraná. As características edáficas da região e o material genético utilizado estão apresentados no quadro 1 .

Quadro 1: Características edáficas da região e material genético utilizado nos plantios

Table 1: Soil characteristics and genetical material used in the stands

\begin{tabular}{|c|c|c|c|}
\hline IDADE & TALHÃO & TIPO DE SOLO & PROCEDÊNCIA \\
\hline 10 & $\begin{array}{l}\text { COLÔNIA } \\
\text { 070B }\end{array}$ & $\begin{array}{l}\text { Latossolo vermelho-escuro, textura } \\
\text { muito argilosa, "A" moderado, ácrico } \\
\text { epidistrófico, fase campo, relevo } \\
\text { suave ondulado e ondulado. }\end{array}$ & $\begin{array}{l}\text { Mudas por sementes, pomar } \\
\text { clonal, procedência Telêmaco } \\
\text { Borba(KLABIN) e origem } \\
\text { Coff's Harbour }\end{array}$ \\
\hline 14 & MORTANDADE 004A & $\begin{array}{l}\text { Latossolo vermelho-escuro, textura } \\
\text { argilosa a muito argilosa, “Ä" } \\
\text { moderado, álico, fase floresta, relevo } \\
\text { suave ondulado e ondulado }\end{array}$ & $\begin{array}{l}\text { Mudas por sementes, pomar } \\
\text { clonal, procedência Telêmaco } \\
\text { Borba(KLABIN) e origem } \\
\text { Coff's Harbour }\end{array}$ \\
\hline 20 & $\begin{array}{l}\text { INVERNADINHA } \\
191\end{array}$ & $\begin{array}{l}\text { Latossolo vermelho-escuro, textura } \\
\text { argilosa, "Ä" moderado, ácrico, fase } \\
\text { floresta, relevo suave ondulado e } \\
\text { ondulado }\end{array}$ & $\begin{array}{l}\text { Mudas por sementes } \mathrm{e} \\
\text { procedência África do Sul }\end{array}$ \\
\hline 25 & $\begin{array}{l}\text { PINHAL BONITO } \\
195\end{array}$ & $\begin{array}{l}\text { Podzólico vermelho-amarelo, textura } \\
\text { argilosa, " } \ddot{A} " \text { moderado, distrófico, } \\
\text { epi-eutrófico, fase floresta, relevo } \\
\text { ondulado }\end{array}$ & $\begin{array}{l}\text { Mudas por sementes e } \\
\text { procedência APS Mogi-Guaçu, } \\
\text { ex-Champion. }\end{array}$ \\
\hline
\end{tabular}

\section{Massa específica básica e aparente}

Para o ensaio de massa específica básica e aparente, utilizaram-se dezesseis árvores (quatro para cada idade), tomando-se as duas primeiras toras, ambas com 0 comprimento comercial de três metros. Da tábua diametral, tomaram-se quatro posições eqüidistantes $(0,33,66$ e 100\%), no sentido medula-casca, com seis repetições por posição, totalizando 768 amostras. As amostras, de formato retangular, apresentaram dimensões de $1,0 \mathrm{~cm} \times 2,0 \mathrm{~cm} \times 3,0 \mathrm{~cm}$, sendo a última medida no sentido longitudinal. $\mathrm{Na}$ determinação do volume das amostras, utilizou-se o método da balança hidrostática, descrito na norma MB 26/40, da ABNT(1940). Para a determinação da massa verde, em condição de umidade de equilíbrio (12\%) e seca em estufa, utilizou-se uma balança digital, com sensibilidade de 0,01g. O ensaio foi realizado no Laboratório de Propriedades Físicas e Mecânicas da Madeira da Universidade Federal de Viçosa, em Viçosa, Estado de Minas Gerais.

\section{Densitometria de raios $X$}

Utilizaram-se três discos de cada árvore, retirados da base, a 3 e 6 metros de altura. Os discos de madeira passaram pelo 
processo de secagem natural até atingir a umidade de equilíbrio. A seguir, retiraram-se amostras radiais da madeira, com seção de 1,0 $\mathrm{cm} \times 1,0 \mathrm{~cm}$. Com um equipamento de dupla serra, retiraram-se amostras de espessura de $1,2 \mathrm{~mm}$, que foram climatizadas a $12 \%$ de umidade até atingirem massa constante, sendo, posteriormente, radiografadas em equipamento de raios $\mathrm{X}$. As radiografias das madeiras foram analisadas em microdensitômetro, que registrou as variações de densidade ótica ao longo das amostras de madeira, no sentido medula-casca. Através de um sistema computacional, os valores foram transformados em massa específica da madeira e apresentados em gráficos. $O$ ensaio de densitometria de raios- $\mathrm{X}$ foi desenvolvido no Laboratório de Identificação e Anatomia de Madeiras do Departamento de Ciências Florestais da ESALQ/USP, utilizando-se técnica descrita por Amaral (1994).

O esquema de retirada das amostras é apresentado na figura 1.

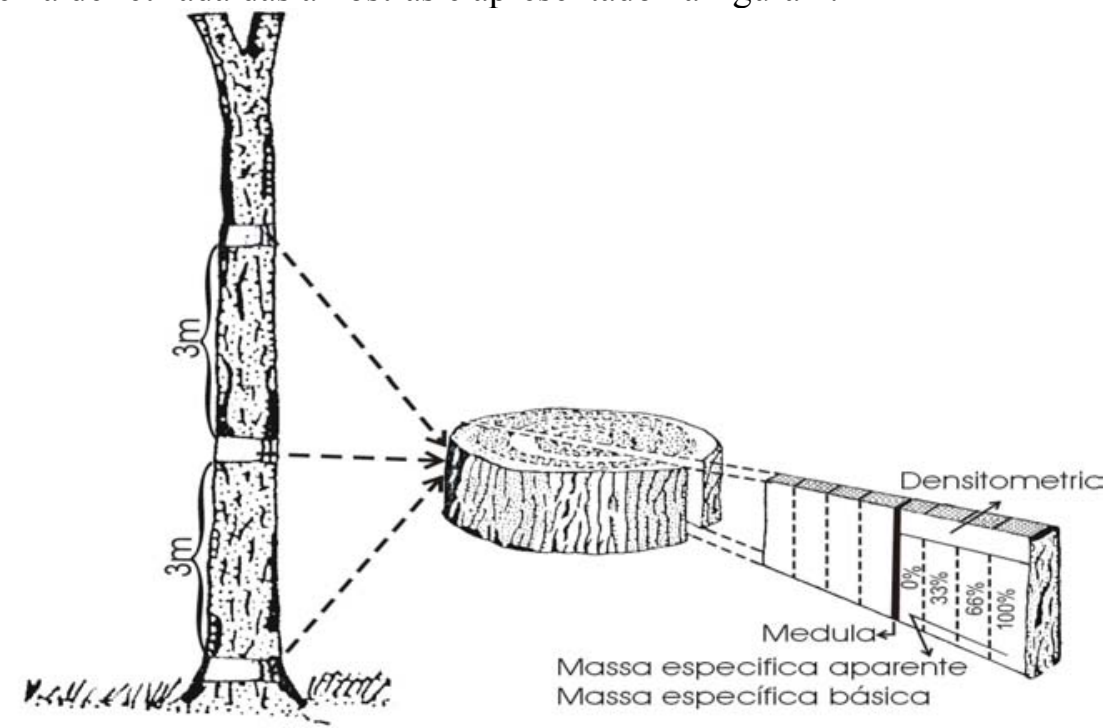

Figura 1: Retirada das amostras para ensaios de massa específica

Figure 1: Layout of sample location within the tree trunk

A análise estatística foi feita através da análise de variância e do teste de médias(Tukey), considerando-se os efeitos da variação da idade e da posição radial no sentido medula-casca, bem como a interação entre os efeitos idade x posição.

\section{RESULTADOS E DISCUSSÃO}

A massa específica apresentou valores crescentes com a idade e com a posição radial no sentido medula-casca. Considerando-se os valores apresentados no Quadro 2, verificou-se a maior variação entre as madeiras de dez e quatorze anos, seguida da variação entre as madeiras de vinte e vinte e cinco anos e, praticamente, não houve variações entre as madeiras de quatorze e vinte e cinco anos. A massa específica da madeira de árvores mais jovens e da região mais próxima da medula apresentou valores mais reduzidos que os encontrados nas madeiras mais maduras e mais próximas da casca. Verificou-se um aumento sistemático da massa específica da madeira com a idade, havendo uma tendência de estabilização, após a idade de vinte anos da árvore, quando se observou ligeiro decréscimo dos valores médios. Os valores mais reduzidos para a madeira de vinte e cinco, quando comparados aos da madeira de vinte anos, possivelmente devem estar relacionados às diferentes condições locais, tratos silviculturais e material genético, conforme os dados anteriormente apresentados no quadro 1

Os valores médios de massa específica e as variações quanto à idade e ao sentido radial, bem como às interações de seus efeitos, estão apresentados no quadro 2 . 
Quadro 2: Valores médios de massa específica $(\mathrm{g} / \mathrm{cm} 3)$ da madeira de Eucalyptus grandis, de diferentes idades e posições no sentido medula-casca $(\mathrm{m}-\mathrm{c})$

Table 2: Average values of specific gravity $(\mathrm{g} / \mathrm{cm} 3)$ of Eucalyptus grandis wood of different ages and at different distances in the pith-to-bark direction

\begin{tabular}{|c|c|c|c|c|c|c|}
\hline \multirow[b]{2}{*}{ TRATAMENTOS } & \multicolumn{3}{|c|}{$\begin{array}{l}\text { MASSA ESPECÍFICA BÁSICA }{ }^{2} \\
\left(\mathrm{~g} / \mathrm{cm}^{3}\right)\end{array}$} & \multicolumn{3}{|c|}{$\begin{array}{l}\text { MASSA ESPECÍFICA APARENTE } \\
\left(\mathrm{g} / \mathrm{cm}^{3}\right)\end{array}$} \\
\hline & MÉDIA & TUKEY & CV $(\%)$ & MÉDIA & TUKEY & $\mathrm{CV}(\%)$ \\
\hline Idade 10 anos & 0,34 & $\mathrm{a}^{1}$ & 9,46 & 0,46 & $\mathrm{a}$ & 12,39 \\
\hline Idade 14 anos & 0,41 & $\mathrm{~b}$ & 11,04 & 0,55 & $\mathrm{~b}$ & 11,27 \\
\hline Idade 25 anos & 0,42 & $\mathrm{~b}$ & 15,89 & 0,55 & $\mathrm{~b}$ & 12,36 \\
\hline Idade 20 anos & 0,47 & $\mathrm{c}$ & 16,96 & 0,60 & $\mathrm{c}$ & 13,66 \\
\hline Posição 0\% (M-C) & 0,37 & $\mathrm{a}$ & 12,49 & 0,47 & $\mathrm{a}$ & 12,55 \\
\hline Posição 33\% (M-C) & 0,37 & $\mathrm{a}$ & 11,80 & 0,50 & $\mathrm{~b}$ & 13,60 \\
\hline Posição 66\% (M-C) & 0,42 & $\mathrm{~b}$ & 14,81 & 0,57 & $\mathrm{c}$ & 13,33 \\
\hline Posição 100\% (M-C) & 0,47 & $\mathrm{c}$ & 18,30 & 0,62 & $\mathrm{~d}$ & 14,03 \\
\hline \multicolumn{7}{|l|}{ Interação idade X posição } \\
\hline 10 anos x posição $0 \%$ & 0,32 & $\mathrm{a}$ & 6,46 & 0,42 & $\mathrm{a}$ & 13,46 \\
\hline 10 anos x posição 33\% & 0,32 & $\mathrm{a}$ & 6,84 & 0,43 & $\mathrm{a}$ & 13,18 \\
\hline 14 anos x posição $0 \%$ & 0,35 & $\mathrm{ab}$ & 11,80 & 0,46 & $\mathrm{ab}$ & 12,27 \\
\hline 25 anos x posição $0 \%$ & 0,36 & $\mathrm{ab}$ & 8,42 & 0,47 & $\mathrm{ab}$ & 12,04 \\
\hline 14 anos x posição $33 \%$ & 0,37 & $\mathrm{ab}$ & 4,75 & 0,48 & $\mathrm{ab}$ & 11,76 \\
\hline 25 anos x posição $33 \%$ & 0,38 & $\mathrm{bc}$ & 5,19 & 0,50 & $\mathrm{bc}$ & 11,31 \\
\hline 10 anos x posição $66 \%$ & 0,38 & bc & 7,48 & 0,51 & $\mathrm{bc}$ & 11,31 \\
\hline 20 anos x posição $0 \%$ & 0,39 & $\mathrm{bc}$ & 10,46 & 0,51 & $\mathrm{bc}$ & 11,08 \\
\hline 10 anos x posição $100 \%$ & 0,40 & $\mathrm{bc}$ & 7,40 & 0,52 & $\mathrm{bc}$ & 10,86 \\
\hline 20 anos x posição 33\% & 0,42 & $\mathrm{~cd}$ & 5,89 & 0,55 & $\mathrm{~cd}$ & 10,12 \\
\hline 25 anos x posição $66 \%$ & 0,43 & de & 7,32 & 0,58 & de & 9,73 \\
\hline 14 anos x posição $66 \%$ & 0,43 & de & 7,10 & 0,60 & de & 9,44 \\
\hline 14 anos x posição $100 \%$ & 0,44 & $\mathrm{e}$ & 7,10 & 0,61 & $\mathrm{e}$ & 9,27 \\
\hline 20 anos x posição $66 \%$ & 0,49 & $\mathrm{e}$ & 7,24 & 0,62 & $\mathrm{e}$ & 9,10 \\
\hline 25 anos x posição $100 \%$ & 0,52 & $\mathrm{e}$ & 7,45 & 0,65 & $\mathrm{e}$ & 8,71 \\
\hline 20 anos x posição $100 \%$ & 0,58 & $\mathrm{f}$ & 8,52 & 0,73 & $\mathrm{f}$ & 7,75 \\
\hline MÉDIA GERAL & 0,41 & & & 0,54 & & \\
\hline
\end{tabular}

${ }^{1}$ Médias seguidas da mesma letra não diferem estatisticamente entre si, pelo teste de Tukey, com significância de $5 \%(\mathrm{p}<0,05)$.

${ }^{2}$. Massa absolutamente seca e volume saturado.

3. Massa e volume ao mesmo teor de umidade (12\%)

Estatisticamente, observou-se uma diferença para massa específica básica e aparente entre as idades de dez, quatorze e vinte anos, mas as madeiras de quatorze e vinte e cinco anos não apresentaram diferenças entre si ; quanto à posição radial, tais diferenças foram observadas entre as posições de 33, 66 e $100 \%$, quando se analisaram os valores médios de massa específica básica; Os valores médios de massa específica aparente na variação radial apresentaram diferenças estatísticas entre si, com significância de 5\%. Verificou-se que os menores valores de massa específica foram aqueles pertencentes às regiões mais próximas da medula e de idade mais reduzida.

Os coeficientes de variação foram relativamente baixos, indicando baixa variabilidade entre os valores utilizados. Tais valores evidenciam um aumento com a idade e com a variação radial, no sentido medulacasca, reflexo de uma maior quantidade e heterogeneidade de material, encontrado nas madeiras de maior idade. Tais valores estão em conformidade com os normalmente citados pela literatura.

Através da análise de variância, detectou-se que os efeitos da posição radial e, principalmente, da idade afetaram significativamente os valores da massa específica; o efeito conjunto de ambos, também, afetou os valores da massa específica, evidenciando a existência de dependência entre os fatores idades e posição radial. 
Quadro 3: Análise de variância da massa específica básica da madeira de Eucalyptus grandis de diferentes idades e posições no sentido medula-casca

Table 3: Variance analysis of specific gravity $\left(\mathrm{g} / \mathrm{cm}^{3}\right)$ of Eucalyptus grandis wood of different ages and at different distances in the pith-to-bark direction

\begin{tabular}{|lrcccc|}
\hline Causa da Variação & G. L. & Soma dos Quadrados & Quadrado Médio & F & P \\
\hline Principais Efeitos & 3 & 1,74418 & 0,581394 & $524,46^{*}$ & 0,0000 \\
A: Idade & 3 & 1,43668 & 0,478892 & $432,00^{*}$ & 0,0000 \\
B: Medula-Casca & & & & 0,0000 \\
Interações & 9 & 0,397842 & 0,0442047 & $39,88^{*}$ & 0,0000 \\
AB & 749 & 0,830311 & 0,00110856 & & \\
Resíduo & 764 & 4,42603 & & & \\
\hline Total (Corrigido) & 764 & & & \\
\hline
\end{tabular}

Nota: * Significativo a 95\% de probabilidade.

Os valores de massa específica básica e aparente apresentaram a mesma tendência e a

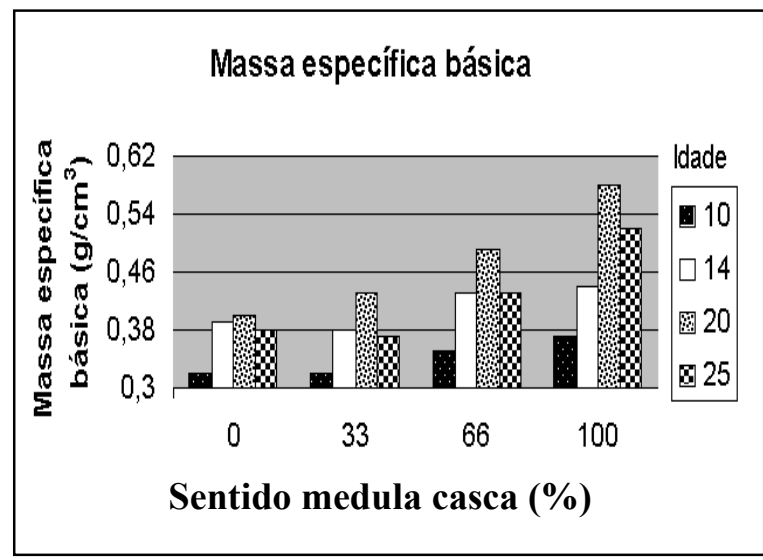

Figura 2: Variação da massa específica básica e aparente $(\mathrm{g} / \mathrm{cm} 3)$ da madeira de Eucalyptus grandis de diferentes idades e posições no sentido medula-casca

Figure 2: Specific gravity variation of Eucalyptus grandis wood of different ages and at different distances in the pith-to-bark direction

O perfil densitométrico apresenta uma análise de variação da massa específica aparente no sentido radial a intervalos de 10 micrômetros. Os valores médios encontrados na análise densitométrica foram muito semelhantes aos encontrados na determinação da massa específica aparente, através do mesma magnitude de variação, o que pode ser comprovado através da figura 1.

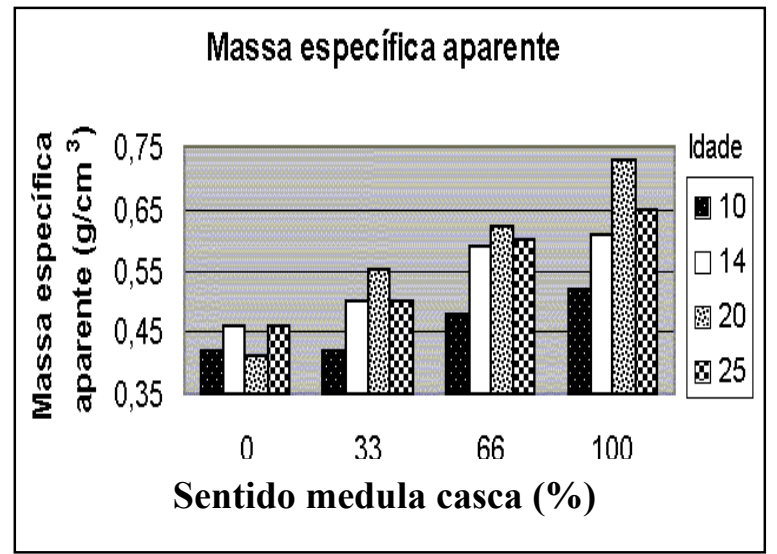

método convencional. Os valores encontrados em todas as posições da idade de dez anos foram inferiores à média geral, em toda a extensão radial, o que pode ser comprovado através do perfil densitométrico, apresentado na figura 3. 


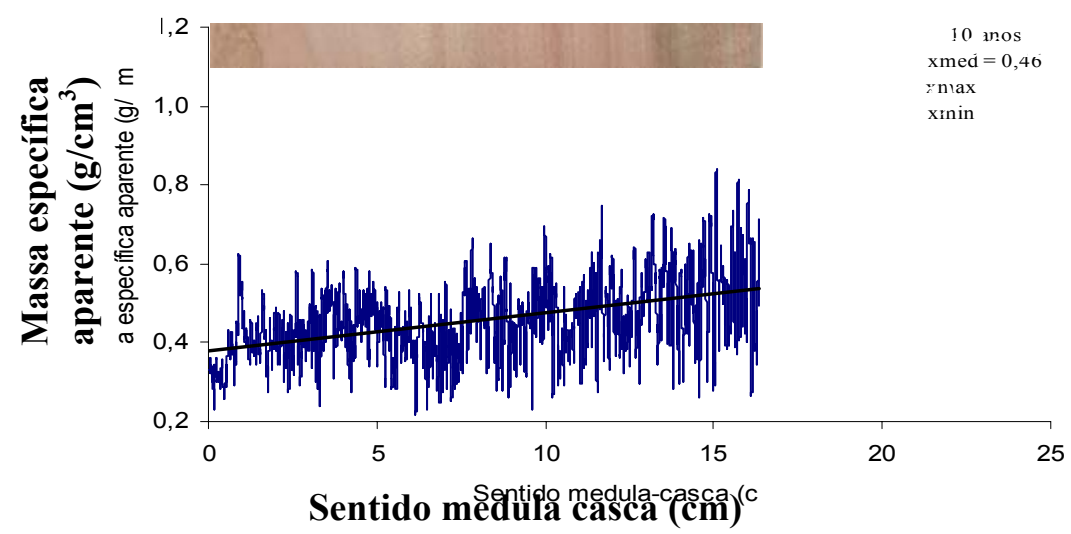

Figura 3: Perfil densitomético da seção radial da madeira de Eucalyptus grandis, com dez anos de idade

Figure 3: Densitometric profile of the radial section of ten year old Eucalyptus grandis

Observando-se a figura 3, verificou-se uma enorme variabilidade dos dados ao longo de toda a extensão radial e se confirmou uma tendência de crescimento da massa específica ao longo da seção radial, no sentido medulacasca. O valor médio da massa específica aparente foi de $0,46 \mathrm{~g} / \mathrm{cm}^{3}$, valor este muito próximo ao obtido para a massa específica aparente, quando obtido pelo método convencional. Embora surgissem algumas oscilações ao longo do perfil, mais da metade da seção radial, localizada na região próxima da medula, situa-se abaixo do valor médio obtido para a massa específica aparente e deve representar a porção de madeira juvenil.

O perfil densitométrico da seção radial da madeira de quatorze anos é representado na figura 4.

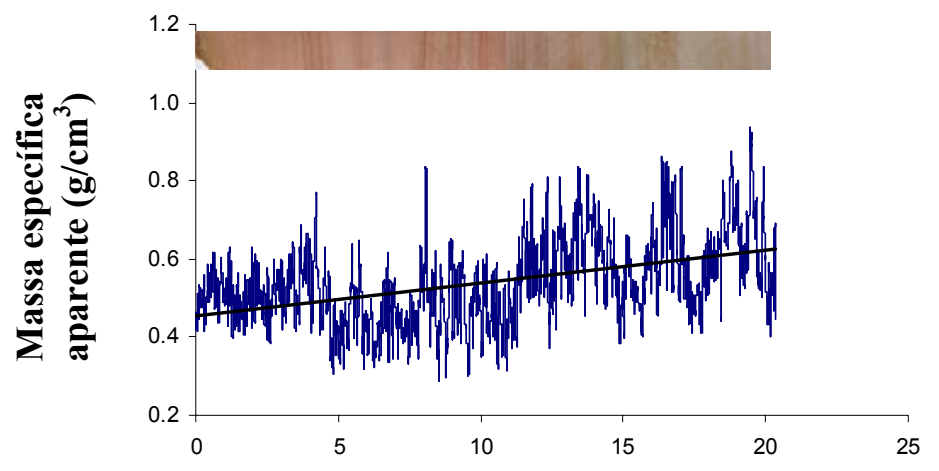

Figura 4: Perfil densitométrico da seção radial da madeira de Eucalyptus grandis, de quatorze anos de idade Figure 4: Densitometric profile of the radial section of fourteen-year-old Eucalyptus grandis

À semelhança do gráfico apresentado na figura 3, observou-se na figura 4 uma enorme variabilidade dos dados e confirmou-se uma tendência de crescimento da massa específica aparente, ao longo da seção radial, no sentido medula-casca. $\mathrm{O}$ valor médio da massa específica aparente foi de $0,54 \mathrm{~g} / \mathrm{cm}^{3}$, superior ao valor médio encontrado na madeira de dez anos. Verificou-se uma alternância de valores ao longo da seção, com um ligeiro decréscimo na porção intermediária, voltando a crescer, provavelmente, na região correspondente à madeira adulta; o decréscimo mencionado se deve a possíveis variações sazonais ou, mesmo, a alterações fisiológicas no processo de formação da madeira; uma considerável porção da seção radial, principalmente da região compreendida entre 5 a $12 \mathrm{~cm}$ do raio no sentido medula-casca, deve corresponder, provavelmente, à porção de madeira juvenil.

O perfil densitométrico da seção radial da madeira de vinte anos é representado na figura 5 . 


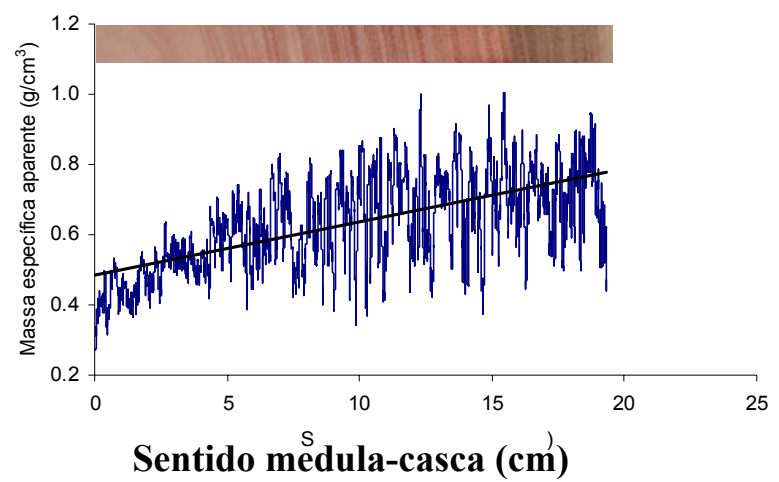

Figura 5: Perfil densitométrico da seção radial da madeira de Eucalyptus grandis, de vinte anos de idade Figure 5: Densitometric profile of the radial section of twenty year old Eucalyptus grandis

Observando-se o gráfico apresentado na figura 5, verificou-se uma enorme variabilidade dos dados e confirmou-se uma tendência de crescimento da massa específica aparente, ao longo da seção radial, no sentido medula-casca. $\mathrm{O}$ valor médio da massa específica aparente foi de $0,63 \mathrm{~g} / \mathrm{cm}^{3}$, superior ao valor médio encontrado em todas as madeiras do trabalho em questão. A maior inclinação da reta comprova a maior diferença entre os limites inferior e superior dos valores encontrados na madeira de vinte anos; os valores médios encontrados na análise densitométrica foram muito semelhantes aos encontrados na determinação da massa específica aparente, através do método convencional, cujos resultados estão apresentados no quadro 2 .

O perfil densitométrico da seção radial da madeira de vinte e cinco anos é representado na figura 6 .

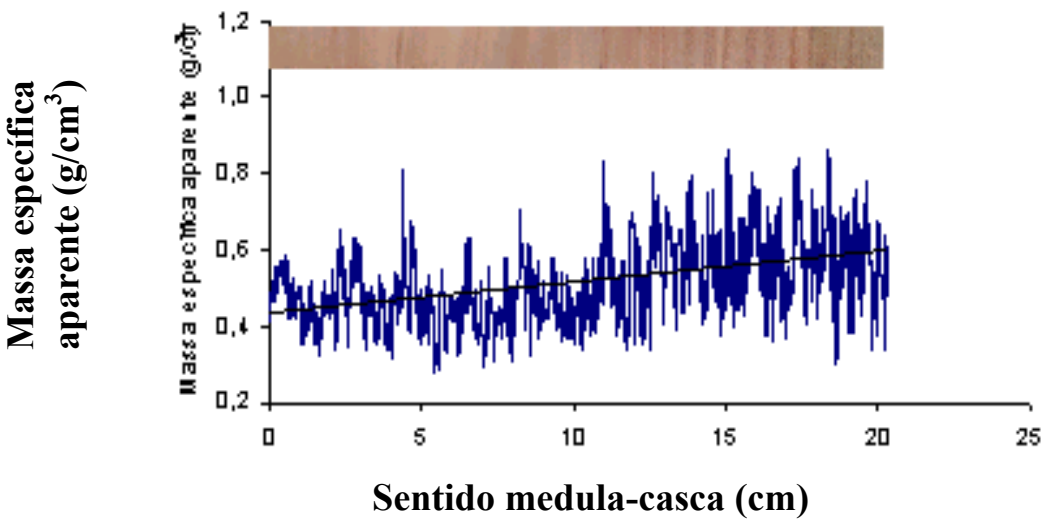

Figura 6: Perfil densitométrico da seção radial da madeira de Eucalyptus grandis, de vinte e cinco anos de idade

Figure 6: Densitometric profile of the radial section of twenty-five year old Eucalyptus grandis

À semelhança do gráfico apresentado na figura 4, observou-se na figura 6 uma enorme variabilidade dos dados e confirmou-se uma tendência de crescimento da massa específica aparente, ao longo da seção radial, no sentido medula-casca. O valor médio da massa específica aparente foi de $0,52 \mathrm{~g} / \mathrm{cm}^{3}$, superior ao valor médio encontrado na madeira de dez anos, mas inferior ao encontrado na madeira de vinte anos. Verificou-se que uma considerável porção da seção radial, principalmente da região próxima da medula, apresenta uma porção de material que deve corresponder à madeira juvenil. A semelhança observada entre as figuras 4 e 6 confirma a semelhança entre a madeira de quatorze e vinte e cinco anos, cujos valores, apresentados no quadro 2 , são muito próximos e nem mesmo apontam diferenças estatísticas entre si.

O menor valor de massa específica aparente de vinte e cinco anos em relação à 
madeira de vinte anos possivelmente se deve à diversidade de material genético e diferentes condições locais de crescimento e tratos silviculturais, apresentados no quadro 1.

\section{CONCLUSÕES}

Com base nos resultados, pode-se concluir que:

- Em todos os ensaios realizados, observou-se uma tendência crescente da massa específica em função da idade e da variação radial, no sentido medula-casca.

- Os menores valores para a massa específica foram encontrados na madeira de dez anos.

- $\quad$ Os maiores valores foram encontrados na madeira de vinte anos, em função de maior quantidade de madeira adulta.

- As madeiras de quatorze e vinte e cinco anos apresentaram valores de massa específica muito próximos entre si e confirmaram a presença de certa porção de madeira juvenil em sua seção radial.

- A madeira de vinte e cinco anos apresentou menores valores de massa específica que a madeira de vinte anos, possivelmente devido à diversidade de material genético e diferentes condições locais de crescimento e tratos silviculturais.

\section{BIBLIOGRAFIA}

ABNT - MB-26/40: ensaios físicos e mecânicos da madeira. Rio de Janeiro, 1940. $16 \mathrm{p}$.

AMARAL, A .C.B. Implantação da metodologia de densitometria de raios-x em madeira. Piracicaba. 1994. 109p. Dissertação (Mestrado, Escola Superior de Agricultura Luiz de Queiroz, Universidade de São Paulo).

BENDTSEN, B. A. ; SENFT, J. Mechanical and anatomical properties in individual growth ring of plantation grown eastern cottonwood and loblolly pine. Madison, Wood and Fiber Science, v. 18, n. 1, p. 23-38. 1986.

BHAT, K. M. et al. - Wood density and fiber lenght of Eucalyptus grandis grown in Kerala,
India. Wood and Fiber Science, Madison, v. 22, n. 1, p. 54-61. 1990.

CARMO, A .P. T. Avaliação de algumas propriedades da madeira de seis espécies de eucalipto. Viçosa (MG), $1996 . \quad 74 p$. Dissertação (Mestrado em Ciência Florestal, Departamento de Engenharia Florestal, Universidade Federal de Viçosa).

CHIMELO, J.P. Development of a probability-based computerized characterization system for identification and for property prediction of selected tropical hardwoods. Blacksburg, 1980. 206p. Tese (Doutorado Virginia Polytechnic Institute and State University)

DELLA LUCIA, R.M. ; VITAL, B.R. Propriedades físicas e mecânicas da madeira de três regiões do tronco de Eucalyptus saligna SM. Revista Árvore, Viçosa, MG, v. 7, n. 1, p. 71-75. 1983.

ENGLERT, G.H. Framework of qualitative relationship in wood utilization. Madison, Forest Products Laboratory, Research Papper FFP 45. 1966, 16p.

FERREIRA, M.; KAGEYAMA, P.Y. Melhoramento genético da densidade da madeira de eucalipto. In: CONGRESSO FLORESTAL BRASILEIRO, 3, São Paulo, SILVICULTURA, v. 14, n. 14, p. 148-152, 1978.

GÉRARD, J. et al.. Qualité du bois chez les eucalyptus de plantation - Etude de variation de trois proprietés de référence. Bois et Forêts des Tropiques, Nancy, n. 245, p. 101-111, 1995.

HILLIS, W. E.; BROWN, A. G. Eucalyptus for wood production. Melbourne: CSIRO, 1978, 434p.

KOLLMANN, F.F.P. ; COTÊ, W. A . Principles of wood science and technology. Berlim: Springer-Verlag, 1968. v. 1, 592p.

LIMA, T.G. Variações no sentido radial e longitudinal de algumas propriedades das madeiras de Eucalyptus microcorys $F$. Muell e Eucalyptus pilularis Sm. Viçosa, MG, 1995.106p. Dissertação ( Mestrado Universidade Federal de Viçosa). 
LIMA, J.T.; BREESE, M. C. ; CAHALAN, C. $M$. Variation in wood density and mechanical properties in Eucalyptus clones. In: THE FUTURE OF EUCALYPTS FOR WOOD PRODUCTS. 2000, Launceston, Tasmania. Proceedings... Launceston: IUFRO. 2000, p. 282-291.

OLIVEIRA, E. et al. Correlações entre parâmetros de qualidade da madeira de Eucalyptus grandis Hill ex-Maiden, Boletim Técnico da SIF, Viçosa(MG), n.2, p.1-9, 1990.

OLIVEIRA， J. T. S. Caracterização da madeira de eucalipto para a construção civil. São Paulo, 1997. 2v., 429p. Tese (Doutorado, Escola Politécnica, Universidade de São Paulo ).

PANSHIN, A . J.; DE ZEEUW, C. Textbook of wood technology. $4^{\text {a }}$ ed. New York, McGraw Hill, 1980, 722p.
TOMAZELLO FILHO, M. Estrutura anatômica da madeira de oito espécies de eucalipto cultivadas no Brasil. IPEF, Piracicaba, v. 29, p. 25-36. 1985a.

TOMAZELLO FILHO, M. Variação radial da densidade básica e da estrutura anatômica da madeira de Eucalyptus saligna e Eucalyptus grandis. IPEF, Piracicaba, v.29, p.37-45, 1985 b.

TSOUMIS, G. Science and technology of wood: Structure, properties and utilization. New York, : Van Nastrnd Reinold, 1991, 494p.

VITAL, B. R. Efeito da idade da árvore na densidade da madeira de Eucalyptus grandis cultivado na região do cerrado de Minas Gerais. Brasília: IBDF, Brasília, 1987, p. 4952. (Boletim Técnico, 8).

ZOBEL, B. J. \& JETT, J. B. Genetic of wood production. Berlin:Spring-Verlag, 1995. 337p. 